\title{
Prosthesis-Related Infection
}

National Cancer Institute

\section{Source}

National Cancer Institute. Prosthesis-Related Infection. NCI Thesaurus. Code C79705.

A bacterial infection related to a device used to replace a missing body part. The infection

may occur during the operation from direct contamination or post-operatively through hematogenous spread. 